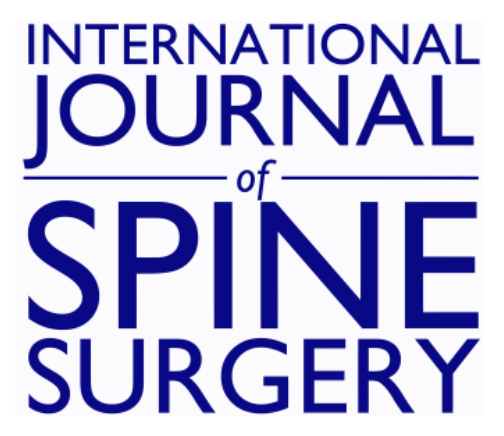

\title{
100 Consecutive Cases of Degenerative Lumbar Conditions Using a Non-Threaded Locking Screw System With a 90-Degree Locking Cap
}

Paul C. McAfee, Bryan W. Cunningham, P. Justin Tortolani, Ira L. Fedder, John C. Sefter and Charles Davis

Int J Spine Surg 2009, 3 (1) 1-11

doi: https://doi.org/10.1016/SASJ-2008-0022-RR

http://ijssurgery.com/content/3/1/1

This information is current as of April 26, 2023.

Email Alerts Receive free email-alerts when new articles cite this article. Sign up at:

http://ijssurgery.com/alerts

The International Journal of Spine Surgery

2397 Waterbury Circle, Suite 1,

Aurora, IL 60504, Phone: +1-630-375-1432

(C) 2009 ISASS. All Rightss Refservedefom http://ijssurgery.com/ by guest on April 26, 2023 


\title{
100 Consecutive Cases of Degenerative Lumbar Conditions Using a Non-Threaded Locking Screw System With a 90-Degree Locking Cap
}

\author{
Paul C. McAfee, MD, , ${ }^{a}$ Bryan W. Cunningham, MSc, ${ }^{a}$ P. Justin Tortolani, MD, , Ira L. Fedder, MD, ${ }^{a}$ \\ John C. Sefter, DO, ${ }^{a}$ and Charles Davis, $M D^{a}$
}

\begin{abstract}
Background

This prospective study analyzes the perioperative outcomes and long-term fusion success of 100 consecutive lumbar degenerative cases. The cases were managed using a non-threaded locking screw system, in conjunction with polyetheretherketone (PEEK) cages, for posterior lumbar interbody fusion (PLIF) procedures. These 100 cases were compared to another prospective study treating patients with the same inclusion and exclusion criteria using conventional plate-based pedicle screw spinal instrumentation augmented with carbon fiber interbody cages.

\section{Methods}

A total of 167 operative levels were treated in 100 patients (51 single-level, 39 two-level and 10 three-level cases). Eleven cases were revisions and 67 patients received interbody fusion cages. Patients had an average of $22.8 \pm 4.0$ months followup. Results: There was one instrumentation failure but no significant subsidence at the interbody fusion level. The disc space height was restored as part of the surgical procedure at the interbody cage levels: from $7.5 \pm 2.3$ mm preoperative to $9.0 \pm 2.1 \mathrm{~mm}$ postoperative. There were 2 cases of pseudarthrosis $(2 / 100=2 \%)$. The average operative time for 1-level cases was $111 \pm 25$ minutes; for 2-level cases it was $132.4 \pm 21.8$ minutes; and for 3-level cases it was $162.6 \pm 33$ minutes. Blood loss averaged $800 \pm 473 \mathrm{cc}$ for 1 -level cases, $1055 \pm 408 \mathrm{cc}$ for 2 levels, and $1155 \pm 714 \mathrm{cc}$ for 3 levels. The length of stay was similar between the 3 groups ( $4.4 \pm 1.2$ days for single-level cases, $4.7 \pm 1.1$ for 2 levels, and $5.0 \pm 1.1$ for 3 levels; $P>.05$ ) There were 3 incidental durotomies, and 4 other patients developed infections postoperatively that required reoperation.

\section{Conclusion}

The disc and foraminal heights can be restored and maintained with a unilateral cage and pedicle screw construct. Unilateral transforaminal lumbar interbody fusion using a PEEK cage combined with a non-threaded locking pedicle screw and rod system results in similar fusion rates to those achieved using the bilateral Brantigan interbody fusion cage or a single BAK Vista implant. When compared to the bilateral Brantigan cages, decreased operative time $(P<.001)$, decreased blood loss $(P<.001)$ and reduced incidence of dural tears $(P<.001)$ are advantages of using a non-threaded locking screw system and single PEEK interbody cage for lumbar degenerative conditions without compromising subsequent fusion rates.
\end{abstract}

Key Words: Deformity, Interbody Fusion, Spinal Instrumentation SAS Journal. March 2009;3:1-10. DOI: SASJ-20080022-RR

a'Scoliosis and Spine Center, St. Joseph's Medical Center, Towson, Maryland 21204

Address correspondence to Paul C. McAfee, MD, Scoliosis and Spine Center, O’Dea Medical Building \#104, 7505 Osler Drive, Towson, MD 21204 USA (e-mail: mack8132@gmail.com)

Paul McAfee, MD, and Bryan Cunningham, MSc, own stock (options) in Pioneer Surgical Technology, Inc. Pioneer Surgical supplied grant assistance for this research.

\section{INTRODUCTION}

In the last 10 years, there have been progressive improvements in pedicle screw spinal instrumentation including polyaxial screw designs, increasing use of titanium to permit improved postoperative imaging, and a transition from the longitudinal plates Variable Screw Placement (VSP) described with the early reports of Brantigan interbody fusion cages towards nearly exclusive use of longitudinal rods for fixation. Posterior lumbar interbody fusion (PLIF) in conjunction with a pedicle screw system allows for decompression of the neural elements as well as circumferential arthrodesis performed through a single, posterior incision. Lumbar spinal fusion has historically been an important surgical tool in stabilization of the lumbar spine, reducing pain and disability. ${ }^{1-6}$ However, there has been a relative lack of consensus on an ideal fusion method demonstrated on many levels, including complication rates and patient outcomes. $^{6-14}$ Carbon fiber rectangular cages were originally introduced to provide anterior load sharing in cases with posterior pedicle instrumentation for patients with degenerative lumbar spine conditions. Carbon fiber cylindrical cages were invented to improve the radiographic assessment of interbody arthrodesis, which 
was difficult with traditional titanium BAK cages. Both shapes of cages are composite structures having $35 \%$ carbon and $65 \%$ polyetheretherketone (PEEK). Newer interbody cages have excluded the matrix carbon fiber and offer material composed of $100 \%$ pure polymeric PEEK. The current investigation reviews data from 100 consecutive lumbar degenerative cases managed with a non-threaded locking screw system and unilateral PEEK interbody fusion cages. The prospective data is used to analyze the perioperative outcomes, adverse events and long-term fusion success of this non-threaded locking screw system in comparison to established, expected clinical outcomes for 360-degree lumbar fusion procedures using conventional plate-based pedicle screw spinal instrumentation augmented with carbon fiber interbody cages.

\section{Figure 1.}
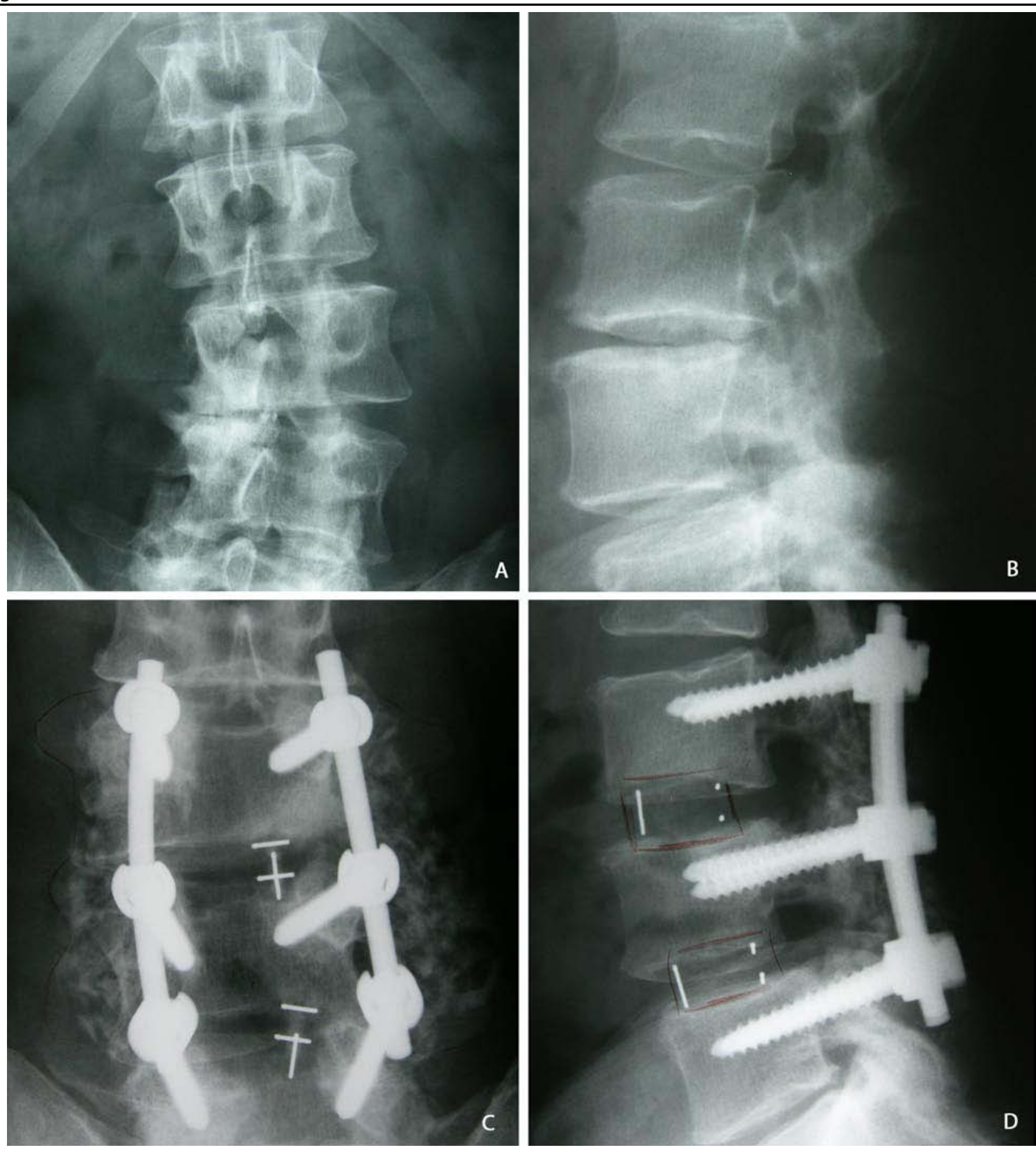

Degenerative Lumbar Scoliosis and Spinal Stenosis:This 59-year-old male presented with degenerative lumbar scoliosis and spinal stenosis (A, B). He underwent posterior decompression from L3-L5 with unilateral interbody PEEK cage and transpedicular screw and rod fixation using the spinal rod system. Intervertebral height and segmental alignment at the L3-L4 and L4-L5 levels were restored following reconstruction (C, D). 


\section{MATERIALS AND METHODS}

Institutional Review Board (IRB) approval was obtained from the participating institution for this project. One hundred consecutive cases of lumbar spine deformity were managed using a non-threaded locking screw system in conjunction with PEEK cages for PLIF procedures performed at St. Joseph's Regional Medical Center in Towson, Maryland, from 2006 to 2007. The primary goal of this prospective study was to compare the perioperative outcomes, efficacy and adverse events of the Quantum Pedicle Screw System used in conjunction with the PEEK-OPTIMA cage (PEEK-PLUS System, Pioneer Surgical Technology, Inc., Marquette, MI) for lumbar degenerative instability, post-laminectomy syndrome, and spondylolisthesis versus historical controls using conventional dual cages (PLIF) and pedicle instrumentation (Figure 1). ${ }^{11,15}$ The Quantum Spinal Rod System (Pioneer Surgical Technology, Inc., Marquette, MI) consists of polyaxial and fixed pedicle screws, straight and bent rods, and crosslinks composed of titanium. The system offers a unique, consistent force locking cap, with an intermediate provisional locking feature that permits segmental compression and distraction for deformity correction while maintaining rod-screw connectivity.

\section{Patient Demographics and Operative Indications}

Forty males (mean age $59 \pm 14$ ) and 60 females (mean age $56 \pm 15$ ) were included in the current study. A total of 167 operative levels were treated in 100 patients (51 single-level, 39 two-level and 10 three-level cases). Eleven cases (11\%) were revisions and 67 patients received PEEK interbody cage implants (Figure 2). The operative indications for the 100 consecutive cases were as follows: post laminectomy syndrome, 25 cases; recurrent herniated nucleus pulposis, 24 cases; isthmic spondylolisthesis, 25 cases; degenerative spondylolisthesis, 15 cases; spinal stenosis, 9 cases; retrolisthesis, 1 case; pseudarthrosis, 1 case. In all cases, a decompressive laminectomy and foraminotomy was performed at nearly all operative levels followed by pedicle screw spinal instrumentation. Only after assuring optimal purchase of the pedicle screws was reconstruction of the anterior spinal column initiated. Shirado et al. ${ }^{16}$ reported that the spinal column becomes more unstable following posterior discectomy or PLIF. For this reason, it was the objective for those cases requiring interbody arthrodesis to perform a thorough discectomy, and restore the intervertebral height gradually through a unilateral PLIF approach. From a technical standpoint, once the discectomy is performed and intervertebral height restored, it is important to continually distract on the contralateral pedicle screws so that the distraction force is distributed to the pedicle screws and all 3 columns rather than being resisted solely by the anterior column. In all cases, the posterolateral and interbody arthrodesis procedures utilized local bone graft combined with demineralized bone matrix (DBM) (Grafton DBM Putty, manufactured by Osteotech, Inc., Eatontown, NJ) within and around the PEEK cages. No iliac crest bone harvesting was required, even in the 11 revision cases.

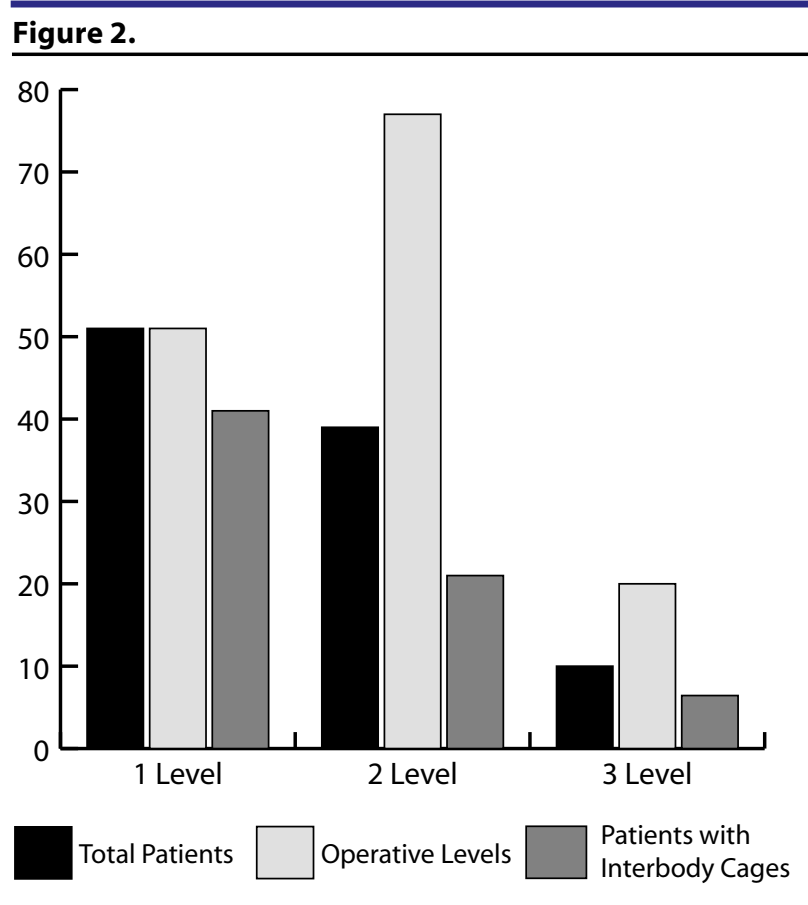

Bar chart demonstrating patient stratification based on number of operative levels and the use of interbody cages. A total of 167 operative levels were treated in 100 patients (51 single-level, 39 two-level and 10 three-level cases). Eleven cases (11\%) were revisions and $67 \%$ patients received PEEK interbody cage implants.

\section{Radiographic Evaluation}

The radiographic assessment of fusion within the intervertebral disc space was classified according to the criteria of Brantigan and Steffee. ${ }^{6}$ A detailed description of the criteria are described in the original article, but an overview of the 5 -point scale is $1=$ obvious radiographic pseudarthrosis; $2=$ probable radiographic pseudarthrosis; $3=$ radiographic status uncertain; $4=$ probable radiographic fusion; and $5=$ radiographic fusion. Posterolateral fusions were evaluated by a single observer (other than the operative surgeon) from the anteroposterior and Ferguson radiographs, according to the method reported by Lenke et al. ${ }^{17}$ They were judged as Grade A, definitely solid with bilateral stout fusion masses present; Grade B, probably solid with a unilateral stout fusion mass and a contralateral thin fusion mass; Grade C, probably not solid with a thin unilateral fusion mass and a probable pseudarthrosis on the contralateral side; or Grade D, definitely not solid with thin fusion masses bilaterally and obvious pseudarthrosis or bone graft dissolution bilaterally. 
Changes in intervertebral disc height, overall lumbar lordosis (L1-S1), and operative level segmental lordosis between preoperative, immediate postoperative and 12-month postoperative plain film radiographs were calculated for those intervertebral levels reconstructed with PEEK interbody cages. Standing lateral plain film images were made using a high resolution digital camera, and intervertebral disc height (millimeters) was measured at the operative level(s) using the vertebral endplates as margins (Figure 3). All calculations were performed using Bersoft Image Measurement system and a semi-automated computer software program designed to determine angles (degrees) and distances (millimeters) from digital images. To ensure reproducibility, a calibration scale containing known angles and distances was scanned, and the digital angles / distances were calculated and compared to actual values. All linear translations were corrected for film magnification error.

Standard perioperative and early postoperative data, including estimated blood loss, duration of surgery and incidence of dural tears, was collected for all 100 patients. Also, the reoperation rate and revision of pedicle screws or cages were tabulated for the spinal rod system treatments versus the carbon-fiber-reinforced I/F cage historical controls. ${ }^{8,17}$ All patients were followed clinically and radiographically, with follow-up periods of 6 weeks and 3, 6, 12, and 24 months following surgery. Anteroposterior (A/P) and lateral radiographs were performed at each prescribed follow-up interval.

\section{RESULTS}

The mean follow-up for all 100 patients was $22.8 \pm 4$ months with a range of 16 to 31 months. The average operative time for single-level cases was $112 \pm 25$ minutes; for 2-level cases, $132 \pm 21$ minutes; and for 3level cases, $163 \pm 33$ minutes. The estimated blood loss averaged $800 \pm 473 \mathrm{cc}$ for single-level cases, $1055 \pm 408$ cc for 2 levels, and $1155 \pm 714 \mathrm{cc}$ for 3 levels. The length of hospitalization following the surgical procedures averaged $4.4 \pm 1.2$ days for single levels, $4.7 \pm 1.1$ days for 2 levels, and $5.0 \pm 1.1$ days for 3 levels $(P>.05)$ (overall range, 4.4 to 5 days). In terms of complications, there were 3 incidental durotomies intraoperatively and 4 postoperative infections, which required reoperation $(4 / 100=4 \%)$. The reoperations entailed irrigation and debridement within the first postoperative week. The 4 patients had 6 weeks of antibiotics and did not require removal of the instrumentation. There were no long-term sequelae as a result of the 4 infections, and there were also no significant cases of radicular symptoms in the followup clinical exams. These findings, in part, are attributable to the unilateral cage placement, which required less retraction of the dura and decreased the exposure of the posterior central disc required for bilateral cage placement. There were no cases of pseudarthrosis or significant subsidence $(>3 \mathrm{~mm})$ at the interbody fusion level.

\section{Figure 3.}
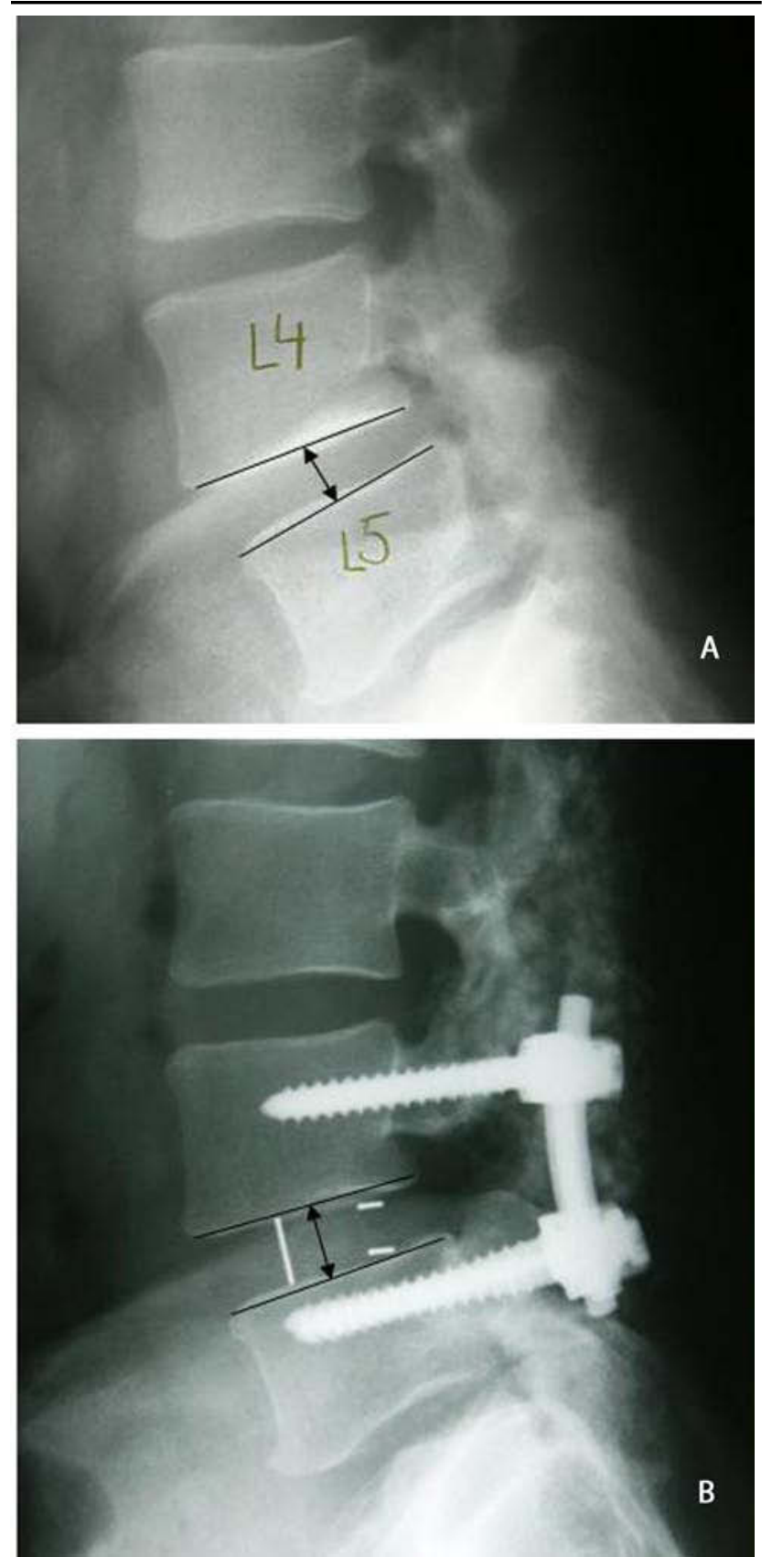

Changes in intervertebral disc height between preoperative, immediate postoperative and 12-month postoperative plain film radiographs were calculated for those intervertebral levels reconstructed with interbody PEEK cages. Intervertebral disc height (millimeters) was measured at the operative level(s) using the vertebral endplates as margins $(A, B)$.

The intervertebral disc space height and foraminal height were restored as part of the surgical procedure. Intervertebral disc height, as measured from the center of the operative level, increased from an average $7.5 \pm 2.3 \mathrm{~mm}$ preoperatively (range of $2.63 \mathrm{~mm}$ to 
$11.34 \mathrm{~mm}$ ) to $9.0 \pm 2.1 \mathrm{~mm}$ postoperatively (range of $5.13 \mathrm{~mm}$ to $12.75 \mathrm{~mm}$ ). This $20 \%$ increase in disc space height decreased on average by $0.9 \pm 1.77 \mathrm{~mm}$ (range of $0.05 \mathrm{~mm}$ to $2.79 \mathrm{~mm}$ ) at one-year follow-up (Figure 4). Segmental lordosis measured at the intervertebral endplate levels decreased from an average of $8.35 \pm 4.42$ degrees preoperatively to $6.74 \pm 3.25$ degrees postoperatively following cage implantation $(P<.05)$. However, overall lumbar lordosis measured from L1 to S1 averaged $42.24 \pm 10.87$ degrees preoperatively and decreased to $41.60 \pm 7.02$ degrees postoperatively $(P>.05)$. There was one case of a crosslink failure but no incidence of pedicle screw / rod breakage or fracture / migration of an interbody cage in the 100 consecutive cases.

\section{Figure 4.}

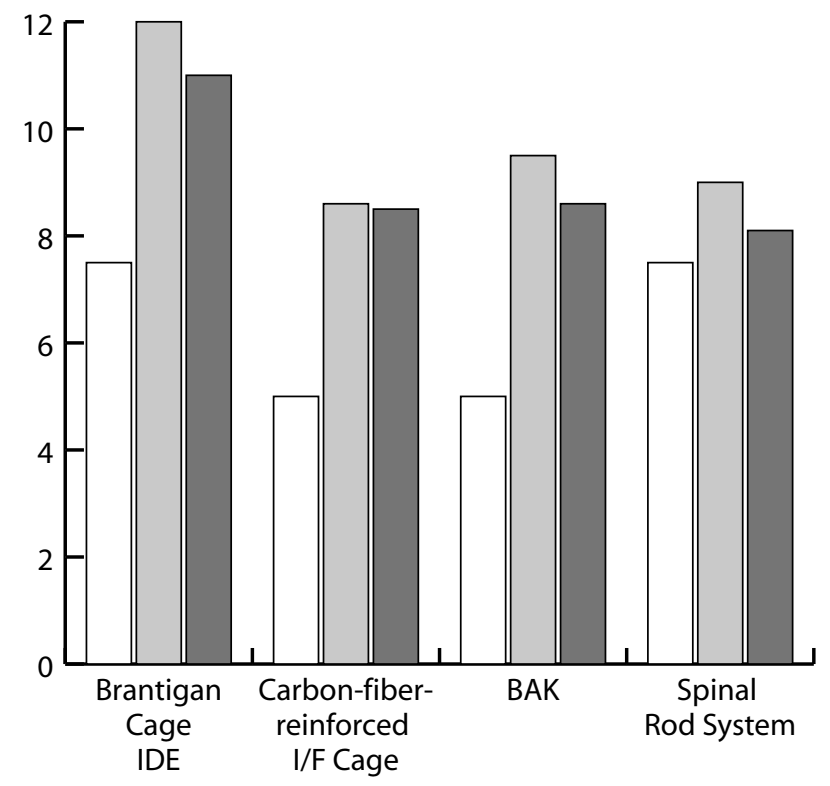

Preoperative

Initial Postop

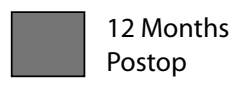

Intervertebral disc height, as measured from the center of the operative level, increased from an average of $7.5 \pm 2.3 \mathrm{~mm}$ preoperatively to 9.0 $\pm 2.1 \mathrm{~mm}$ postoperatively for the spinal rod ystem with interbody PEEK cages. This $20 \%$ increase in disc space height decreased on average by $0.9 \pm 1.77 \mathrm{~mm}$ at 1 -year follow-up. These values closely approximate those that were reported by Brantigan et al..$^{8}$ (Brantigan IDE) and McAfee et al. ${ }^{17}$ (carbon-fiber-reinforced cage and BAK)

In the total 167 levels, there were no return visits to the operating room for pseudarthrosis of the 360-degree fusion. According to the Classification of Fusion criteria of Brantigan and Steffee ${ }^{6}$ for transforaminal lumbar interbody fusion (TLIF), there was no evidence of probable (Brantigan Grade 2) or obvious (Brantigan Grade 1) radiographic pseudarthrosis. Even in the cases where the interbody arthrodesis was indeterminate (Brantigan Grade 3), there were no cases of pedicle screw or rod instrumentation failure, no pedicle screw loosening, and no windshield wiper-type signs, so presumably in these cases the posterolateral arthrodesis was mature enough to prevent instability at 2 years postoperatively (Figure 5).

\section{DISCUSSION}

The current investigation prospectively reviews data from 100 consecutive degenerative lumbar cases managed with a non-threaded locking screw system and analyzes the perioperative outcomes and longterm fusion success with comparison to historical controls treating cases with the same inclusion and exclusion criterion using carbon fiber cages. Compared to Brantigan et al's historical series, ${ }^{11}$ these 100 cases had more significant preoperative deformities and instabilities, with nearly one-half ( $\sim 50$ cases $)$ being done for spondylolisthesis involving lumbar scoliosis with lumbar spinal stenosis and neurogenic claudication, requiring posterior deformity correction at the time of nerve root decompression. The 100 consecutive cases were compared to an additional series of 100 cases in 90 patients who underwent BAK carbon fiber TLIF ( 80 primary cases and 10 two-level cases), as reported by McAfee et al. ${ }^{15}$ The carbon fiber cylindrical BAK was used for 100 levels in the 90 patients. Thirty-eight of those cases $(38 \%)$ were revisions. All patients had a minimum of 2 years' follow-up (mean $=35.1$ months, range 24 to 66 months). Table 1 compares the incidence of dural tears, length of operative procedure, estimated blood loss, and morbidity of the current series of 100 cases versus the Brantigan FDA investigational device exemption (IDE) clinical trial ${ }^{11}$ and 120 cases that used the carbon-fiber-reinforced I/F cage and BAK as reported by McAfee et al.15 The average overall surgical time, estimated blood loss and incidence of intraoperative durotomies was significantly higher for the clinical IDE Brantigan series versus all other treatments $(P<.05)$.

For each treatment modality, the intervertebral disc space height and foraminal height were restored as part of the surgical procedure. However, it's interesting to note that the disc height lost at healing was greatest for the cylindrical BAK $(1.4 \mathrm{~mm})$ versus the carbon-fiberreinforced $\mathrm{I} / \mathrm{F}$ cage $(0.2 \mathrm{~mm}$ to $0.6 \mathrm{~mm})$ and PEEK cage $(0.9 \mathrm{~mm})$. One potential reason for this difference would be the intraoperative preparation of the endplates. The cylindrical cages instrumentation is designed to partially ream through the vertebral endplates, while the rectangular PEEK/carbon fiber cages tend to restore the disc space height gradually using Collis twisting distracting shavers to prepare a "press-fit" rectangular hole the exact size of the desired cage. Theoretically, the rectangular cage should have less subsidence than the cylindrical variety. This series offered only trends, as we found no statistical differences between the four groups in disc space height change $(P>.05)$. This is probably 


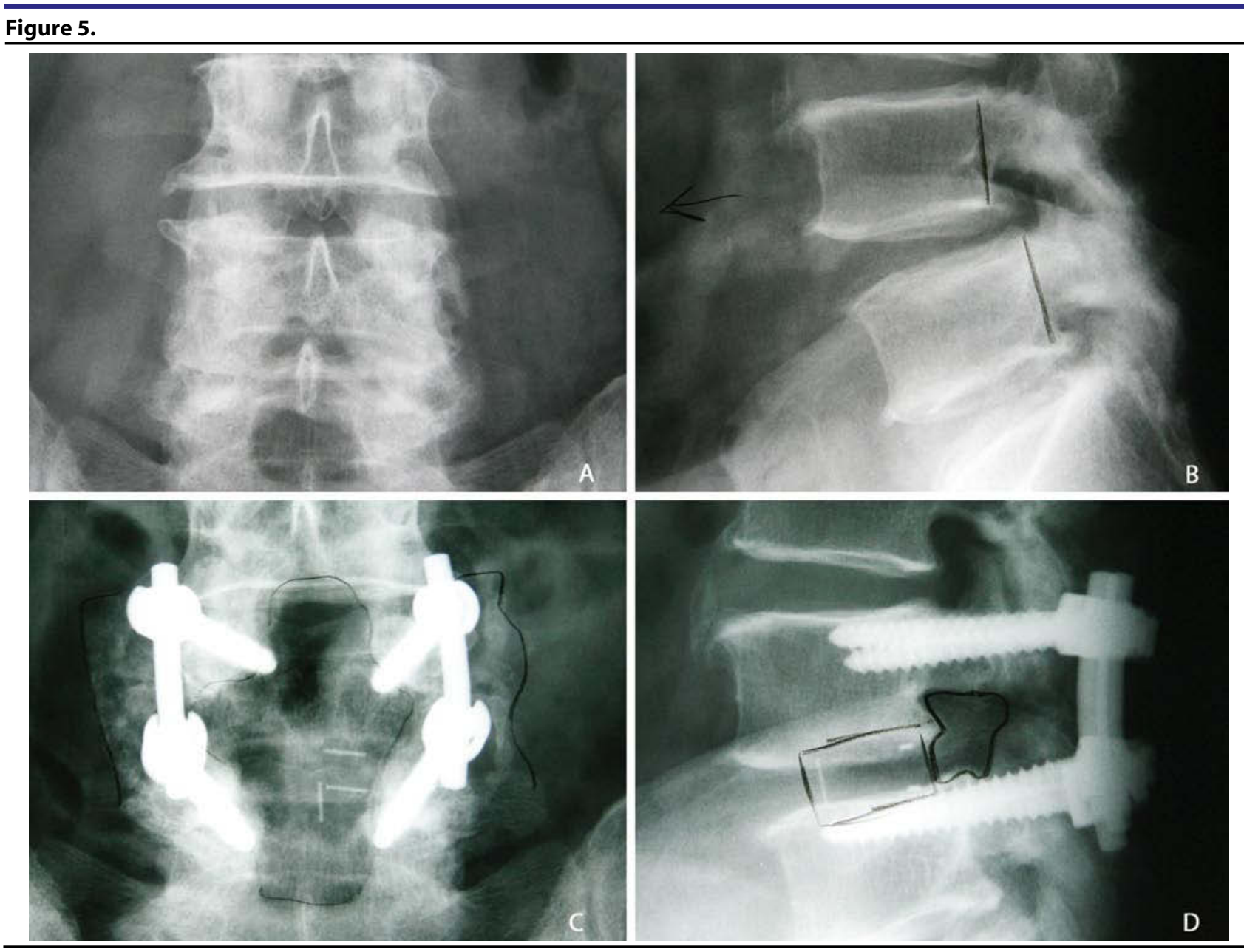

This 74-year-old male presented with an L4-5 Grade I isthmic spondylolisthesis and spinal stenosis (A, B). He underwent reconstruction at the L4-5 level, which included posterior decompression, discectomy with unilateral interbody PEEK cage implantation, and posterior rod instrumentation using the spinal rod system (C, D). As evidenced in the lateral plain films, interbody and posterior reconstruction restored intervertebral and neuroforaminal heights.

\begin{tabular}{|c|c|c|c|c|c|}
\hline & Brantigan Cage IDE & $\begin{array}{l}\text { Carbon-fiber- } \\
\text { reinforced Cage }\end{array}$ & BAK & Spinal Rod System & $P$ value \\
\hline \multicolumn{6}{|l|}{ Mean Length } \\
\hline Follow-Up (Months) & 24 Months & 35.1 Months & & $22.8 \pm 4$ Months & \\
\hline Surgical Time (Minutes) & $297 \pm 82(175-633)^{*}$ & $151.71 \pm 40(70-225) \#$ & $137.44 \pm 53(72-228)$ & $125.2 \pm 29.2(70-203)$ & $P=0.000^{\mathrm{a}, \mathrm{b}}$ \\
\hline EBL (ml) & $\begin{array}{l}1577 \pm 1246 \\
(100-8200)^{\mathrm{a}} \\
\end{array}$ & $\begin{array}{l}695.5 \pm 423 \\
(100-1700) \\
\end{array}$ & $\begin{array}{r}812.14 \pm 504 \\
(200-2500)\end{array}$ & $\begin{array}{l}942.1 \pm 504 \\
(300-2600) \\
\end{array}$ & $P=0.000^{\mathrm{a}}$ \\
\hline Dural Tears & $41 / 221(18.6 \%)^{* *}$ & $7 / 100(7 \%)$ & $8 / 100(8 \%)$ & $3 / 100(3.0 \%)$ & $P=0.000^{c}$ \\
\hline \multicolumn{6}{|l|}{ Disc Space Height (mm) } \\
\hline Preoperative & 7.9 & 5.7 & 5.6 & 7.55 & \\
\hline Intitial Postop & 12.3 & 9 & 10.3 & 9 & \\
\hline Lost at Healing & 0.6 & 0.2 & 1.4 & 0.94 & \\
\hline Reoperation Rate & $102 / 221(46.1 \%)^{c}$ & $5 / 100(5 \%)$ & $3 / 100(3 \%)$ & $4 / 1004.0 \%)$ & $P=0.000^{c}$ \\
\hline \multicolumn{6}{|l|}{ Revision of Pedicle } \\
\hline Screws or cages & $5 / 221(2.2 \%)$ & $1 / 100(1 \%)$ & $0 / 100(0 \%)$ & $0 / 102(0 \%)$ & NS \\
\hline Fusion Success & $176 / 178(98.9 \%)$ & $98 / 100(98 \%)$ & $100 / 100(100 \%)$ & $100 / 100(100 \%)$ & NS \\
\hline Reference & ${\text { Brantigan et } a l^{8}}^{8}$ & McAfee et $\mathrm{al}^{17}$ & McAfee et al ${ }^{17}$ & & \\
\hline \multicolumn{6}{|c|}{$\begin{array}{l}\text { The average overall surgical time, estimated blood loss and incidence of intraoperative durotomies was significantly higher for the clinical IDE } \\
\text { Brantigan series versus all other treatments }(P<.05) \text {. For each treatment modality, the intervertebral disc space height and foraminal height were } \\
\text { restored as part of the surgical procedure. However, it's interesting to note that the disc height lost at healing was greatest for the cylindrical BAK }(1.4 \\
\mathrm{mm}) \text { vs the carbon-fiber-reinforced cage }(0.2 \text { to } 0.6 \mathrm{~mm}) \text { and PEEK cage }(0.9 \mathrm{~mm}) \text {. }\end{array}$} \\
\hline \multicolumn{6}{|c|}{$\begin{array}{l}\left.\text { alndicates difference from all other treatments; }{ }^{b} \text { significantly greater than spinal rod system (ANOVA, } P<.05\right) \text {. }{ }^{\text {V Versus all }}\left(\mathrm{X}^{2} \text { Comparison of Contingenc) }\right. \\
\text { Tables). NS = Not significant at } P<.05\end{array}$} \\
\hline
\end{tabular}


due to the protective effect of the posterior pedicle screw instrumentation and the 360-degree arthrodesis. The nonlocking screw system used in the current study consists of polyaxial and fixed pedicle screws, straight and bent rods and crosslinks composed of titanium. The spinal rod system offers a unique, consistent force locking cap, with an intermediate provisional locking feature that permits safe segmental compression and distraction for reconstruction of degenerative spinal conditions.

Our laboratory is experienced in this technology with 3 previous basic scientific investigations analyzing carbon fiber reinforced polymers. Shono et a ${ }^{18}$ showed superior biomechanical compressive stability in a calf spine model where even in 2-level corpectomy reconstruction, stackable carbon-fiber reinforced PEKEKK (polyether ketone ether ketone ketone) was more rigid than iliac structural bone graft. Brantigan et $\mathrm{al}^{19}$ demonstrated that carbon fiber reinforced cages had greater compressive bench top stability than autograft or allograft from 5 different bone bank preparations. Moreover, Brantigan et $\mathrm{al}^{20}$ developed an animal model in the Spanish goat that showed at 6, 12 and 24 months, carbon-fiber reinforced cages packed with autograft had more successful arthrodesis rates than ethylene oxide sterilized allograft bone. Importantly, this clinical study showed that PEKEKK cages, when inserted as a TLIF, can restore anterior column support in more unstable lumbar conditions.

\section{CONCLUSION}

The current investigation was designed to compare the use and efficacy of a new non-threaded locking pedicle screw and rod system, combined with posterior lumbar interbody arthrodesis, for surgical management of patients presenting with lumbar degenerative instability, postlaminectomy syndrome, and spondylolisthesis versus historical controls using conventional dual cages (PLIF) and pedicle instrumentation. In terms of clinical outcomes, the intervertebral disc height, and thus foraminal height, can be restored and maintained with a unilateral cage and pedicle screw construct. However, average operative level segmental lordosis significantly decreased following cage implantation from a preoperative angle of 8.35 degrees to 6.74 degrees postoperatively $(P<.05)$. This segmental decrease of 1.61 degrees did not affect the overall average postoperative change in lumbar lordosis (preoperative $=$ 42.24 degrees; postoperative $=41.60$ degrees; $P>.05$ ). Unilateral transforaminal lumbar interbody fusion using a PEEK cage combined with a non-threaded locking pedicle screw and rod system for lumbar degenerative conditions results in fusion rates similar to those achieved using the bilateral carbon-fiber-reinforced $\mathrm{I} / \mathrm{F}$ cage or a single BAK. When compared to bilateral $\mathrm{I} / \mathrm{F}$ cages at a single level, decreased operative time, less estimated blood loss and a reduced incidence of dural tears are potential advantages of using a non-threaded locking screw system and single PEEK interbody cage for lumbar degenerative correction, without compromising postoperative stability and subsequent fusion rates.

This article was submitted on September 4, 2008, and accepted for publication on February 25, 2009.

\section{REFERENCES}

1. Blumenthal S, McAfee PC, Guyer RD, et al. A prospective, randomized, multicenter Food and Drug Administration investigational device exemptions study of lumbar total disc replacement with the CHARITÉ artificial disc versus lumbar fusion: part I: evaluation of clinical outcomes. [erratum, Spine. 2005;15;30(20):2356]. Spine. 2005;30(14):1565-1575; discussion E387-391.

2. Delamarter RB, Bae HW, Pradhan BB. Clinical results of ProDisc-II lumbar total disc replacement: report from the United States clinical trial. Orthop Clin North Am. 2005; 36(3):301-13. Review.

3. Fritzell P, Hagg O, Nordwall A, et al. Complications in lumbar fusion surgery for chronic low back pain: comparison of three surgical techniques used in a prospective randomized study. A report from the Swedish Lumbar Spine Study Group. Eur Spine J. 2003;12(2):178-189.

4. Fritzell P, Hagg O, Wessberg P, et al. Chronic low back pain and fusion: a comparison of three surgical techniques: a prospective multicenter randomized study from the Swedish lumbar spine study group. Spine. 2002;27(11):1131-1141.

5. Leufven C, Nordwall A. Management of chronic disabling low back pain with 360 degrees fusion: results from pain provocation test and concurrent posterior lumbar interbody fusion, posterolateral fusion, and pedicle screw instrumentation in patients with chronic disabling low back pain. Spine. 1999;24:2042-2045.

6. Steffee AD, Sitkowski DJ. Posterior lumbar interbody fusion and plates. Clin Orthop. 1988;227: 99-102.

7. Brantigan JW. Pseudarthrosis rate after allograft posterior lumbar interbody fusion with pedicle screw and plate fixation. Spine. 1994;19:1271-1280.

8. Brantigan JW. Carbon fiber interbody fusion cages: indications, results, and radiographic interpretation of fusion. Spine, State of the Art Reviews.1997;11:287-306.

9. Brantigan JW, Steffee AD. A carbon fiber implant to aid interbody lumbar fusion: two-year clinical results in the first 26 patients. Spine. 1993;18:2106-2117.

10. Brantigan JW, Steffee AD, Geiger JM. A carbon fiber implant to aid interbody lumbar fusion: mechanical testing. Spine. 1991;16: S277-S282.

11. Brantigan JW, Steffee AD, Lewis ML, Quinn LM, Persenaire JM. Lumbar interbody fusion using the Brantigan $\mathrm{I} / \mathrm{F}$ cage for posterior lumbar interbody fusion and the variable pedicle screw placement system: two-year results from a Food and Drug Administration investigational device exemption clinical trial. Spine. 2000;25:14371446.

12. Enker P, Steffee AD. Interbody fusion and instrumentation. Clin Orthop. 1994;30:90-101.

13. Madan SS, Boeree NR. Comparison of instrumented anterior interbody fusion with instrumented circumferential lumbar fusion. Eur Spine J. 2003;12(6):567-575. 
14. Tulberg T, Brandt B, Rydberg J, Fritzell P. Fusion rate after posterior lumbar interbody fusion with carbon fiber implant: one-year followup of 51 patients. Eur Spine J. 1996;5:178-182.

15. McAfee PC, DeVine JG, Chaput CD, et al. The indications for interbody fusion cages in the treatment of spondylolisthesis: analysis of 120 cases. Spine. 2005;30(6 suppl):S60-65.

16. Shirado O, Zdeblick TA, McAfee PC, Warden KE. Biomechanical evaluation of methods of posterior stabilization of the spine and posterior lumbar interbody arthrodesis for lumbosacral isthmic spondylolisthesis: a calf spine model. J Bone Joint Surg Am. 1991;73A:518-526.

17. Lenke LG, Bridwell KH, Bullis D, Betz R, Baldus C, Schoenecker PL. Results of in-situ fusion for isthmic spondylolisthesis. $J$ Spinal Disord. 1992;5:433-442.

18. Shono Y, McAfee PC, Cunningham BW, Brantigan JW. A biomechanical analysis of decompression and reconstruction methods in the cervical spine: emphasis on a carbon fiber composite cage. J Bone Joint Surg Am. 1993;75-A:1674-1684.

19. Brantigan JW, Cunningham BW, Warden K, McAfee PC, Steffee AD. Compression strength of donor bone for posterior lumbar interbody fusion. Spine. 1993;18(9):1213-1221.

20. Brantigan JW, McAfee PC, Cunningham BW, Wang H, Orbegoso $\mathrm{CM}$. Interbody lumbar fusion using a carbon fiber cage implant versus allograft bone: an investigational study in the Spanish goat. Spine. 1994;19:1436-1444. 


\section{EXTENDED REFERENCES}

A prospective, randomized, multicenter Food and Drug Administration investigational device exemptions study of lumbar total disc replacement with the CHARITE artificial disc versus lumbar fusion: part I: evaluation of clinical outcomes.

Blumenthal S, McAfee PC, Guyer RD, Hochschuler SH, Geisler FH, Holt RT, Garcia R Jr, Regan JJ, Ohnmeiss DD.

STUDY DESIGN: A prospective, randomized, multicenter, Food and Drug Administration-regulated Investigational Device Exemption clinical trial. OBJECTIVES: The purpose of this study was to compare the safety and effectiveness of lumbar total disc replacement, using the CHARITE artificial disc (DePuy Spine, Raynham, MA), with anterior lumbar interbody fusion, for the treatment of single-level degenerative disc disease from L4-S1 unresponsive to nonoperative treatment. SUMMARY OF BACKGROUND DATA: Reported results of lumbar total disc replacement have been favorable, but studies have been limited to retrospective case series and/or small sample sizes. METHODS: Three hundred four (304) patients were enrolled in the study at 14 centers across the United States and randomized in a 2:1 ratio to treatment with the CHARITE artificial disc or the control group, instrumented anterior lumbar interbody fusion. Data were collected pre- and perioperatively at 6 weeks and at 3,6, 12, and 24 months following surgery. The key clinical outcome measures were a Visual Analog Scale assessing back pain, the Oswestry Disability Index questionnaire, and the SF-36 Health Survey. RESULTS: Patients in both groups improved significantly following surgery. Patients in the CHARITE artificial disc group recovered faster than patients in the control group. Patients in the CHARITE artificial disc group had lower levels of disability at every time interval from 6 weeks to 24 months, compared with the control group, with statistically lower pain and disability scores at all but the 24 month follow-up $(P<0.05)$. At the 24-month followup period, a significantly greater percentage of patients in the CHARITE artificial disc group expressed satisfaction with their treatment and would have the same treatment again, compared with the fusion group $(P<0.05)$. The hospital stay was significantly shorter in the CHARITE artificial disc group $(P<0.05)$. The complication rate was similar between both groups. CONCLUSIONS: This prospective, randomized, multicenter study demonstrated that quantitative clinical outcome measures following lumbar total disc replacement with the CHARITE artificial disc are at least equivalent to clinical outcomes with anterior lumbar interbody fusion. These results support earlier reports in the literature that total disc replacement with the CHARITE artificial disc is a safe and effective alternative to fusion for the surgical treatment of symptomatic disc degeneration in properly indicated patients. The CHARITE artificial disc group demonstrated statistically significant superiority in two major economic areas, a 1-day shorter hospitalization, and a lower rate of reoperations (5.4\% compared with $9.1 \%$ ). At 24 months, the investigational group had a significantly higher rate of satisfaction $(73.7 \%)$ than the $53.1 \%$ rate of satisfaction in the control group $(P=0.0011)$. This prospective randomized multicenter study also demonstrated an increase in employment of $9.1 \%$ in the investigational group and $7.2 \%$ in the control group.

The indications for interbody fusion cages in the treatment of spondylolisthesis: analysis of 120 cases.

McAfee PC, DeVine JG, Chaput CD, Prybis BG, Fedder IL, Cunningham $B W$, Farrell DJ, Hess SJ, Vigna FE.

STUDY DESIGN: This study retrospectively examines outcomes of unilateral transforaminal lumbar interbody fusion (TLIF) with posterior fixation using anterior carbon fiber cages and 360 degrees fusion in spondylolisthesis. OBJECTIVES: The goals were to examine the outcomes and perioperative complications of using anterior column support in the treatment of various types of spondylolisthesis. SUMMARY OF BACKGROUND DATA: In 2000, Brantigan et al reported the Brantigan interbody fusion cage used as a posterior lumbar interbody fusion in the US IDE clinical trial. This is the largest series to date of TLIF cages specifically used in the treatment of spondylolisthesis. METHODS: A comprehensive long-term follow-up study was conducted to evaluate the fusion success and morbidity following implantation with an anterior column support and posterior pedicle screw fixation. The 120 patients with spondylolisthesis were comprised by 11 cases, dysplastic; 58 cases, degenerative; and 51 cases, isthmic-acquired spondylolisthesis. Anterior column support was either a rectangular carbon fiber/PEEK device or a cylindrical carbon fiber/PEEK device. Twenty-eight cases (23\%) were revisions. RESULTS: There were no pseudarthrosis, instrumentation failures, or significant subsidence at the TLIF level. The disc space height and foraminal height were restored as part of the surgical procedure. Disc height, as measured from the posterior edge of the superior vertebral body, increased from a mean of $5.6 \mathrm{~mm}$ before surgery to a mean of $9.3 \mathrm{~mm}$ after surgery. Although reduction of the slip was not the primary goal during the surgical procedure for the 120 cases with spondylolisthesis (isthmic-acquired $=51$, degenerative $=58$, and dysplastic $=11$ ), the $23 \%$ slip reduction achieved at surgery was maintained at follow-up. Mean operative time was 143 +/- 33 minutes (range, 70-255 minutes) for all cases. Mean blood loss was $724+/-431 \mathrm{~mL}$ (range, 300-2,500 mL).There were seven incidental durotomies and three infections. One patient with Grade I degenerative spondylolisthesis required revision of the carbon fiber cage for posterior migration secondary to a traumatic event 3 months after surgery. Fusion success was $98 \%$ using the criteriaof Lenke for the posterior fusion and Brantigan and Steffee for the TLIF graft incorporation. CONCLUSIONS: Interbody cages in spondylolisthesis are useful to increase neuroforaminal height, to facilitate reduction, and to improve the chances of achieving a successful 360 degrees fusion.

A carbon fiber implant to aid interbody lumbar fusion. Two-year clinical results in the first 26 patients.

\section{Brantigan JW, Steffee AD.}

The success of posterior lumbar interbody fusion (PLIF) has been limited by mechanical and biologic deficiencies of the donor bone. The authors have designed a carbon fiber-reinforced polymer implant that separates the mechanical and biologic functions of PLIF. The cagelike implant provides an actual device designed to meet the mechanical requirements of PLIF and replaces the donor bone with autologous bone, the best possible bone for healing. The authors report 2-year follow-up results for their first 26 consecutive patients, 18 of whom were postsurgical failed backs with a total of 37 previous surgeries. At 2 years, 28 of 28 PLIF cage fusion levels and 6 of $11(54.5 \%)$ allograft levels exhibited radiographic fusion, a statistically significant difference at $P=0.0002$. Clinical results were excellent in $11 / 26$, good in $10 / 26$, fair in $3 / 26$, and poor in $2 / 26$. Fair and poor results were attributable to objective identifiable problems unrelated to the carbon cage. The carbon implant achieved successful fusion in $6 / 6$ $(100 \%)$ of followed patients treated for a failed ETO allograft interbody fusion. A prospective controlled multi-centered study is being initiated.

Lumbar interbody fusion using the Brantigan $\mathrm{I} / \mathrm{F}$ cage for posterior lumbar interbody fusion and the variable pedicle screw placement system: two-year results from a Food and Drug Administration investigational device exemption clinical trial.

\section{Brantigan JW, Steffee AD, Lewis ML, Quinn LM, Persenaire JM.}

STUDY DESIGN: A carbon fiber-reinforced polymer cage implant filled with autologous bone was designed to separate the mechanical and biologic functions of posterior lumbar interbody fusion. OBJECTIVES: To test the safety and efficacy of the carbon cage with pedicle screw fixation in a 2 year prospective study performed at six centers under a protocol approved by the Food and Drug Administration, and to present the data supporting the Food and Drug Administration approved indications. SUMMARY OF BACKGROUND DATA: The success of posterior lumbar interbody fusion has been limited by mechanical and biologic deficiencies of the donor bone. Some failures of pedicle screw fixation may be attributable to the absence of adequate load sharing through the anterior column. Combining an interbody fusion device with pedicle screw fixation may address some limitations of posterior lumbar interbody fusion or pedicle screw fixation in cases that are more complex mechanically. METHODS: This clinical study of posterior lumbar interbody fusion with pedicle screw 
fixation involved a prospective group of 221 patients. RESULTS: Fusion success was achieved in 176 (98.9\%) of 178 patients. In the management of degenerative disc disease in patients with prior failed discectomy surgery, clinical success was achieved in $79(86 \%)$ of 92 patients, and radiographic bony arthrodesis in $91(100 \%)$ of 91 patients. Disc space height, averaging $7.9 \mathrm{~mm}$ before surgery, was increased to $12.3 \mathrm{~mm}$ at surgery and maintained at $11.7 \mathrm{~mm}$ at 2 years. Fusion success was notdiminished over multiple fusion levels. These results were significantly better than those reported in prior literature. Although significant surgical complications occurred, those attributable to the implant devices occurred less frequently and generally were minor. CONCLUSIONS: The Brantigan I/F Cage for posterior lumbar interbody fusion and the Variable Screw Placement System are safe and effective for the management of degenerative disc disease.

Complications in lumbar fusion surgery for chronic low back pain: comparison of three surgical techniques used in a prospective randomized study. A report from the Swedish Lumbar Spine Study Group.

Fritzell P, Hägg O, Nordwall A; Swedish Lumbar Spine Study Group.

The reported complication rates after various surgical techniques used to create a lumbar fusion vary within wide ranges. In a previous paper, the Swedish Lumbar Spine Study Group have reported on the clinical outcome of lumbar spine fusion for chronic low back pain in a comparably homogeneous patient population where there were no significant differences between baseline sociodemographic, clinical and paraclinical characteristics. In this report we compared the complication rates of the surgical procedures used in that study and analyzed the association between complications and baseline variables, and between outcome results and complications. A multicenter randomized study was conducted where 211 patients aged 25-65 were treated with lumbar fusion according to three different surgical techniques: noninstrumented posterolateral fusion (PLF, $\mathrm{n}=71$ ), instrumented posterolateral fusion (VSP, $\mathrm{n}=68$ ), and in the third procedure we added an interbody fusion with solid autogenous bone grafts (" $360 ", n=72$ ). We categorized complications as: early/late, major/ minor. The association between complications and sociodemographic characteristics (age, gender, comorbidity, previous surgery, smoking), and technical variables (surgical technique, levels fused, hospital category) was analyzed. The association between outcome variables (patient global assessment, pain, disability, depressive symptoms) and complications was analyzed. A literature review was conducted. There was no mortality. There was no significant difference in clinical outcome between the surgical groups after 2 years, although the power to detect such a difference was low. The total complication rate after 2 years in the PLF group was $12 \%$, compared with $22 \%$ in the $\mathrm{VSP}$ group, and $40 \%$ in the " 360 " group $(\mathrm{P}=0.0003)$. After exclusion of complications, there was still no difference in outcome between the groups. The odds ratio (confidence intervals) of having a complication was 5.3 (2.2-12.7) when "360" was used compared with PLF, and 2.4 (1.1-5.3) for " 360 " compared with VSP. There was no association between clinical outcome and complications on a group level. The reintervention rate was $6 \%$ in the PLF group, $22 \%$ in the VSP, and $17 \%$ in the " 360 " group $(\mathrm{P}=0.020)$. The odds ratio (confidence intervals) of having a reintervention was 4.0 (1.3-11.9) when instrumentation was used compared with non-instrumented fusion. In this prospective randomized study comparing three lumbar fusion techniques in a comparably homogeneous patient population, complications increased significantly with increasing technicality of the surgical procedure. Even though we did not find a significant association between clinical outcome and complications after 2 years, the increased morbidity inflicted on an individual patient was not negligible. In this light, and as no fusion technique produced superior clinical outcome irrespective of whether complications were included or excluded in the analyses, the patient and the treating physician should carefully discuss the possible advantages and drawbacks of the different surgical options before making a decision. In order to make valid comparisons of both complication and reintervention rates after lumbar fusion, there is a need for a consensus in the spinal society regarding the definition of these entities. 


\section{SUPPLEMENTARY DATA}

Table 1. Lumbar Total Disc Replacements in the United States by Gender, 2004-2007

\begin{tabular}{lcc}
\hline & Count & $\%$ \\
\hline Male & 107 & $47.6 \%$ \\
Female & 118 & $52.4 \%$ \\
\hline Total & 225 & $100.0 \%$ \\
\hline
\end{tabular}

Table 2. Lumbar Total Disc Replacement Charges in the United States by Gender, 2004-2007

\begin{tabular}{|c|c|c|}
\hline & Count & Average Charge \\
\hline Male & 107 & $\$ 69,250$ \\
\hline Female & 118 & $\$ 63,502$ \\
\hline Mean & 225 & $\$ 66,201$ \\
\hline \multicolumn{3}{|c|}{$\begin{array}{l}\text { Table 3. Anterior Lumbar Fusion in the United States by } \\
\text { Gender, 2004-2007 }\end{array}$} \\
\hline & Count & $\%$ \\
\hline Male & 2,378 & $41.7 \%$ \\
\hline Female & 3,318 & $58.3 \%$ \\
\hline Total & 5,696 & $100.0 \%$ \\
\hline
\end{tabular}

Table 4. Anterior Lumbar Fusion Charges in the United States by Gender, 2004-2007

\begin{tabular}{lll}
\hline & Count & Average Charge \\
\hline Male & 2,378 & $\$ 99,601$ \\
Female & 3,318 & $\$ 102,082$ \\
\hline Mean & 5,696 & $\$ 101,042$ \\
\hline
\end{tabular}

Table 5. Lumbar Total Disc Replacement Patients

Subsequently Undergoing Lumbar Fusion (Cumulative)

\begin{tabular}{lccccc}
\hline Gender & Count & $\begin{array}{c}>=6 \\
\text { months }\end{array}$ & $\begin{array}{c}>=\mathbf{1 2} \\
\text { months }\end{array}$ & $\begin{array}{c}>=18 \\
\text { months }\end{array}$ & $\begin{array}{c}>=\mathbf{2 4} \\
\text { months }\end{array}$ \\
\hline Male & 107 & 0 & 2 & 2 & 2 \\
\% of patients & & $0.0 \%$ & $1.9 \%$ & $1.9 \%$ & $1.9 \%$ \\
Female & 118 & 4 & 6 & 7 & 7 \\
\% of patients & & $3.4 \%$ & $5.1 \%$ & $5.9 \%$ & $5.9 \%$ \\
Total & 225 & 4 & 8 & 9 & 9 \\
\% of patients & & $1.8 \%$ & $3.6 \%$ & $4.0 \%$ & $4.0 \%$ \\
\hline
\end{tabular}

Table 6. Lumbar Fusion Patients Subsequently Undergoing Refusion (Cumulative)

\begin{tabular}{llllll}
\hline Gender & Count & $\begin{array}{l}\text { >= 6 } \\
\text { months }\end{array}$ & $\begin{array}{l}\text { >= 12 } \\
\text { months }\end{array}$ & $\begin{array}{l}\text { >= 18 } \\
\text { months }\end{array}$ & $\begin{array}{l}\text { >= 24 } \\
\text { months }\end{array}$ \\
\hline Males & 2,378 & 9 & 17 & 25 & 28 \\
\% of patients & & $0.4 \%$ & $0.7 \%$ & $1.1 \%$ & $1.2 \%$ \\
Females & \multirow{2}{*}{, 318} & 16 & 26 & 38 & 43 \\
\% of patients & & $0.5 \%$ & $0.8 \%$ & $1.1 \%$ & $1.3 \%$ \\
Total & \multirow{2}{*}{5,696} & 22 & 43 & 63 & 71 \\
\% of patients & & $0.4 \%$ & $0.8 \%$ & $1.1 \%$ & $1.2 \%$ \\
\hline
\end{tabular}

Table 7. AnteriorLumbar Fusion Patients Subsequently Undergoing Another Fusion, Including Refusions (Cumulative)

\begin{tabular}{llllll}
\hline Gender & Count & $\begin{array}{l}>=\mathbf{6} \\
\text { months }\end{array}$ & $\begin{array}{l}>=12 \\
\text { months }\end{array}$ & $\begin{array}{l}>=\mathbf{1 8} \\
\text { months }\end{array}$ & $\begin{array}{l}>=\mathbf{2 4} \\
\text { months }\end{array}$ \\
\hline Males & 2,378 & 26 & 46 & 58 & 66 \\
\% of patients & & $1.1 \%$ & $1.9 \%$ & $2.4 \%$ & $2.8 \%$ \\
Females & \multirow{2}{*}{318} & 46 & 61 & 76 & 83 \\
\% of patients & & $1.4 \%$ & $1.8 \%$ & $2.3 \%$ & $2.5 \%$ \\
Total & 5,696 & 72 & 107 & 134 & 149 \\
\% of patients & & $1.3 \%$ & $1.9 \%$ & $2.4 \%$ & $2.6 \%$ \\
\hline
\end{tabular}

Table 8. Aggregate Accumulated Orthopedic-related Charges Before Anterior Lumbar Fusion by Time Interval

\begin{tabular}{cccccc}
\hline $\begin{array}{c}\mathbf{1 4} \text { days } \\
\text { prior }\end{array}$ & $\begin{array}{c}\mathbf{3 0} \text { days } \\
\text { prior }\end{array}$ & $\begin{array}{c}\mathbf{9 0} \text { days } \\
\text { prior }\end{array}$ & $\begin{array}{c}\mathbf{6} \\
\text { months }\end{array}$ & $\mathbf{1}$ year & $\mathbf{2}$ years \\
$\$ 1,897$ & $\$ 3,000$ & $\$ 7,499$ & $\$ 11,426$ & $\$ 16,467$ & $\$ 20,562$ \\
\hline
\end{tabular}

Table 9. Aggregate Accumulated Orthopedic-related Charges Before Lumbar Total Disc Replacment by Time Interval

\begin{tabular}{|c|c|c|c|c|c|}
\hline $\begin{array}{l}14 \text { days } \\
\text { prior }\end{array}$ & $\begin{array}{c}30 \text { days } \\
\text { prior }\end{array}$ & $\begin{array}{c}90 \text { days } \\
\text { prior }\end{array}$ & $\begin{array}{c}6 \\
\text { months }\end{array}$ & 1 year & 2 years \\
\hline$\$ 1,021$ & $\$ 1,517$ & $\$ 3,442$ & $\$ 5,349$ & $\$ 11,695$ & $\$ 14,818$ \\
\hline
\end{tabular}

PearlDiver data regarding the clinical procedures/diagnoses described in this paper is derived from HIPAA compliant insurance, private payer sources. These tables and charts are for information purposes only. The PearlDiver data has been obtained or derived from sources believed by PearlDiver to be reliable, but PearlDiver Technologies Inc. does not represent that the information is $100 \%$ accurate or complete. For more information, go to http://pearldiverinc.com 